\title{
Outcome of treatment among chronic lymphocytic leukemia and its correlation to Rai staging system in Kurdistan region of Iraq
}

\author{
Zhala Ahmad* , Kawa Hasan** , Hisham Al-Rawi" ${ }^{\star \star \star}$, Ahmed K. Yassin** , Bryar Rashid* , Tavan \\ Mahmood $^{\star}$, Zaki Mohamed ${ }^{\star \star \star}$, Nawshirwan Mohammed ${ }^{\star \star \star \star \star}$, Sana Jalal ${ }^{\star \star \star}$, Basil Abdulla*, Dana \\ Abdullah* $^{\star}$ Shokhan Mustafa** Shlan Mohammed** , Lara Abdulrahman ${ }^{\star \star}$, Marwa Karam $^{\star \star}$,

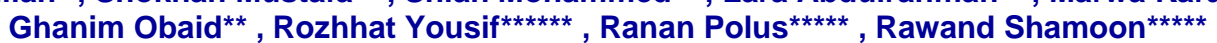 \\ *Hiwa Hemato-onoclogy center, ${ }^{\star \star}$ Nanakali Hemato-oncology center, ${ }^{\star \star \star}$ Sulaimaniah University , ${ }^{* \star \star *}$ University \\ of Duhok, ${ }^{* \star \star \star \star}$ Hawler Medical University, ${ }^{\star \star \star \star \star \star}$ Duhok hematology hospital \\ Correspondence: dr.zhala.ahmad@gmail.com
}

(Ann Coll Med Mosul 2021; 43 (2):100-108).

Received: $27^{\text {th }}$ April 2021; Accepted: $27^{\text {th }}$ June 2021.

\section{ABSTRACT}

Background: Chronic lymphocytic leukemia is common adulthood leukemia with low incidence in Kurdistan region of Iraq. Staging of chronic lymphocytic leukemia is essential in treatment planning and the pattern of response is variable.

Aim of study: To evaluate the Rai staging distribution of patients with chronic lymphocytic leukemia in Kurdistan region/Iraq and its correlation with the treatment outcome.

Patients \& Methods: A retrospective cross sectional review study conducted in three Hemato/oncology centers in Kurdistan for duration of eleven years through the period from $1^{\text {st }}$ of January, 2010 to $31^{\text {st }}$ of December, 2020 on convenient sample of 170chronic lymphocytic leukemia patients. Diagnosis of chronic lymphocytic leukemia was done according to the International Workshop on Chronic Lymphocytic Leukemia. The Rai staging was done by the clinical hematologist in Hemato/oncology center according to clinical evaluation and laboratory investigations. The pattern of the treatment response was determined according to the International Workshop on Chronic Lymphocytic Leukemia (iwCLL)

Results: The Rai staging of our patients was 0 in $15.3 \%$ of them, stage I in $12.4 \%$, stage II $30 \%$, stage III $13.5 \%$ and stage IV $28.8 \%$. The treatment response of studied sample was complete response $(43.5 \%)$, partial response $(17.6 \%)$, stable $(14.1 \%)$, no response $(21.8 \%)$ and progressive $(2.9 \%)$.A highly significant association was observed between no response to treatment and advanced Rai staging and also a highly significant association was observed between death outcome of patients and advanced Rai staging.

Conclusions: The treatment response of patients with chronic lymphocytic leukemia is directly related to Rai staging as patients with advanced Rai staging had lower treatment response rate.

Keywords: Chronic Lymphocytic Leukemia, Rai staging, Treatment response.

$$
\begin{aligned}
& \text { مخرجات العلاج لاى مرضى سرطان الام الليمفاوي المزمن في }
\end{aligned}
$$

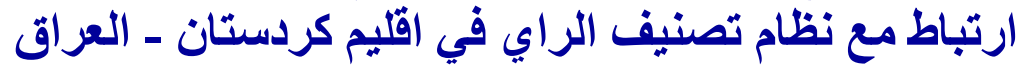

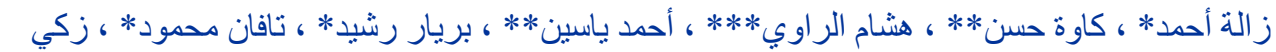

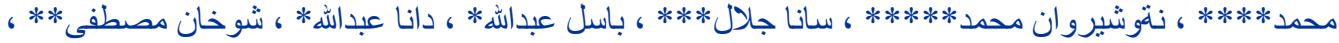

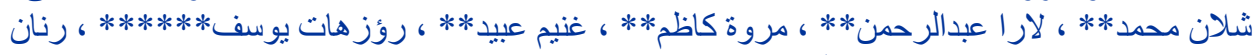

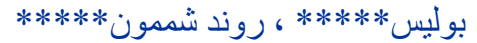

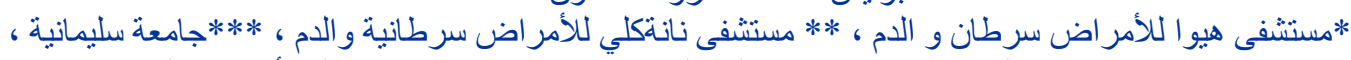

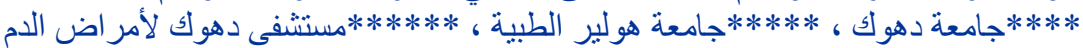

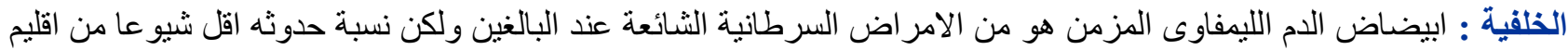

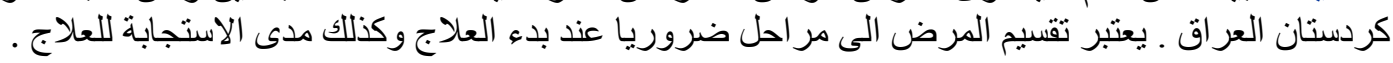


هدف الار اسة : لمعرفة توزيع راى التدريجى للمرضى المصابين بسرطان الدم الليمفاوى المزمن فى إقليم كردستان / العراق و تقييم العلاقة مع نتيجة العلاج.

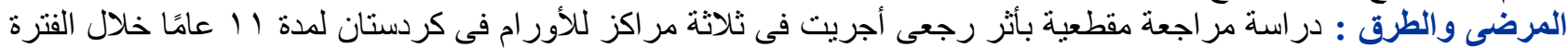

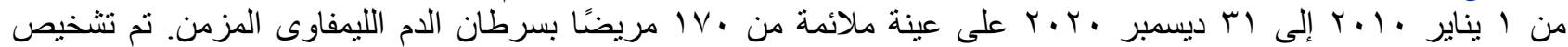

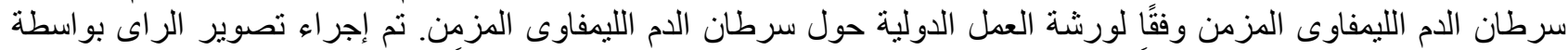

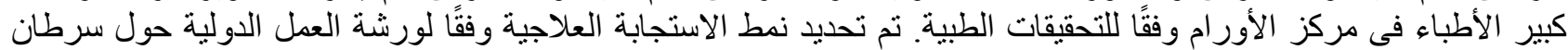

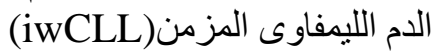

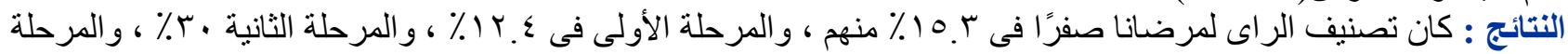

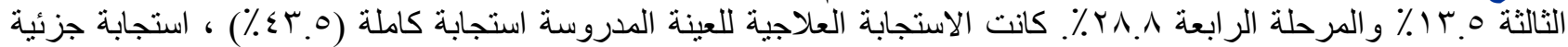

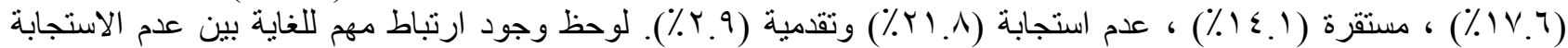

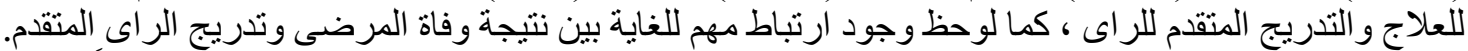

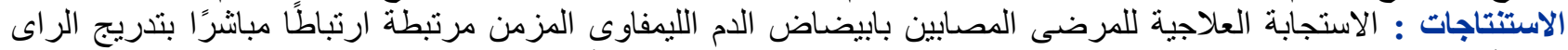

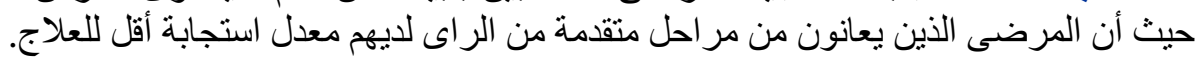

الكلمات المفتاحية : سرطان الدم الليمفاوى المزمن ، نظام تصنيف راى ، نمط الاستجابة للعلاج .

\section{INTRODUCTION}

hronic lymphocytic leukemia (CLL) is the commonest adulthood leukemia in western countries affecting older age population 1. However, the incidence of CLL is low in Asia especially in Middle East countries ${ }^{2}$. The CLL is slightly prevalent in male gender population ${ }^{3}$.Till now, exact etiology of CLL is obscure, with role of genes and environment as predisposing factors. Genetic theory in pathogenesis of CLL is superimposed by low CLL incidence in East countries and positive family history of some CLL patients ${ }^{4}$. Although the CLL is known as a naïve Bcell lymphocytes neoplasm, there is a role for postgerminal center ${ }^{5}$.

Patients with chronic lymphocytic leukemia mainly asymptomatic at diagnosis, but if symptomatic, the symptoms of CLL are variable and presented with unclear symptoms of general weakness or fatigue ${ }^{6}$.Generally, at time of CLL diagnosis, most patients are well. At diagnosis, the lymphadenopathy is recorded in most of patients, splenomegaly is observed in about half of patients, while the hepatomegaly is less incident ${ }^{7,8}$. In some rare CLL cases and with disease progression, the patients presented with accidental reduction of weight, fever and night sweats (B symptoms) ${ }^{9}$. The blood picture of CLL patients manifested mainly by lymphocytosis, in addition to anemia and thrombocytopenia (15-30\% of cases) ${ }^{7,8}$. The cornerstone in CLL diagnosis is explored by peripheral blood immunophenotyping through increased $\mathrm{CD}^{+} / \mathrm{CD}^{2} 3^{+}$monoclonal B lymphocytes level in Peripheral Blood in duration of more than 3 months ${ }^{10}$.

The Rai and Binet clinical staging of CLL were firstly used at seventies of last Century and still utilized till now. These staging systems are easily applied clinically as they are dependable on clinical data taking in consideration anemia, thrombocytopenia, liver, spleen and lymph nodes involvement. Despite that, some CLL cases at Rai stages 0 and 1 or Binet stage $A$ showed rapidly progressive disease, whilst the other CLL cases reported stability of disease status in several years $^{7,8}$. The Rai staging is classified into five groups (0. I, II, III and IV) and Binet stages are grouped into three categories ( $A, B$ and $C$ ). Many literatures evaluated the role of many risk factors affecting prognosis of CLL other than clinical and biological prognostic factors like male gender, higher white blood cell count, increase in lymphocyte in short duration, abnormal bone marrow histopathology ${ }^{11}$ with increased beta-2 microglobulin, lactate dehydrogenase and other markers likeCD23 and thymidine in addition to prognostic markers detected by flow cytometry such as CD38 and ZAP-70 protein $^{12}$. In spite of prognostic role of these markers, the clinical staging has higher sensitivity in detecting the burden of CLL and in prediction of CLL disease progression $^{9}$. In addition to the role of the state of the mutation of mutated immunoglobulin heavy chain variable region (IGHV), 17p deletion and TP53 mutation is important before initiation of therapy, they are expensive and requires delicate technical efforts which limits its application routinely in clinical practice ${ }^{13}$.

Treatment of CLL is designed according clinical staging and specific guidelines ${ }^{14}$. CLL patients at early stage (Rai stage 0 , Binet stage $A$ ) require no treatment and accompanied with long survival ${ }^{7,8}$. CLL patients at intermediate stage (Rai stage I or II, Binet stage B) are treated if accompanied with 
disease activity signs and have median survival of eight years, while CLL patients at advanced stage (Rai stage III or IV, Binet stage C) must have treatment and characterized by short survival. Nowadays, the CLL survival becomes longer as new effective drugs have been introduced ${ }^{15,16}$.

The CLL is long duration incurable disease. For that, it requires long duration follow up and observation. The treatment response of CLL should be done at least two months after completing the recommended therapy by physical examination and evaluating the bone marrow. Treatment response is dependable firstly on major symptoms and burden of tumor (lymph nodes, liver and/or spleen size, constitutional symptoms and lymphocyte count) and secondly on hematopoietic system (platelets count, hemoglobin and bone marrow findings). Treatment response is classified into complete remission (CR), partial remission $(\mathrm{PR})$, stable disease (SD) and progressive disease (PD) ${ }^{15}$.

The aim of present study is to evaluate the Rai staging distribution of patients with chronic lymphocytic leukemia in Kurdistan region/Iraq and its correlation with the treatment outcome.

\section{PATIENTS AND METHODS}

This study was a retrospective cross sectional review study conducted in three Hemato/oncology centers in three cities of Kurdistan region (Hiwa Cancer Hospital, Nanakali Hospital, Duhok Hematology Center). The duration of the study was eleven years through the period from $1^{\text {st }}$ of January, 2010 to $31^{\text {st }}$ of December, 2020. All patients with a diagnosis of CLL whom have been diagnosed at, and/or referred to regional hematology-oncology centers during study duration were the study population. The inclusion criteria included patients with CLL from all age groups, diagnosed by flow cytometry ( BD FACSCanto $^{\text {TM }}$ II flow Cytometry) or bone marrow biopsy with immunohistochemistry who completed treatment. Small lymphocytic leukemia (SLL), Monoclonal B cell lymphocytosis of $<5000$ monoclonal lymphocytes / $\mathrm{mm}^{3}$, Richter's syndrome, B-cell prolymphocytic leukemia, Hairycell leukemia,disease duration of less than one year, patients were not treated, patients refused treatment, missed data and the leukemic phase of indolent NHL (follicular, splenic marginal zone, mantle cell lymphoma)were excluded from the study. The ethical considerations were implemented according Helsinki Declaration regarding ethical approval of Health authorities, an ethical approval was taken from Kurdistan Board Ethical Committee and confidentiality of data. A convenient sample of 170 chronic lymphocytic leukemia patients was selected after eligibility to inclusion and exclusion criteria.

The data were collected by the researcher from saved records of patients in three Hemato/oncology center $s$ and some information were collected directly from patients and fulfilling a prepared questionnaire. The questionnaire was designed by the researcher and the supervisor. The questionnaire included the followings: general characteristics of CLL patients (age, gender, residence, Binet stage and Rai staging) treatment characteristics (treatment type and treatment cycles) and outcome (Treatment response, current status and survival duration). The chemotherapy treatment of studied CLL patients was Chlorambucil, Bendamustine-Rituximab and lbrutinib and FCR (Fludarabine + Cyclophosphamide + Rituximab). Sixty-three CLL patients were treated by FCR as frontline treatment and 107 CLL patients were treated by other chemotherapies and as followings; 47 patients by Bendamustine-Rituximab, 37 patients by Chlorambucil and 23 patients by lbrutinib.

The age of CLL patients was categorized into five groups and ranged from 28 years to 88 years. The residence of CLL patients was distributed into three cities of Kurdistan region. The Binet and Rai staging of CLL patients was done by the clinical hematologist in Hemato/oncology center according to medical and investigations findings ${ }^{7,8}$. Additionally, the Rai staging was grouped into low risk, moderate risk and high risk according to updated Rai staging. The treatment response was assessed by the researcher and supervisor according to iwCLL ${ }^{14}$ into five categories (complete response, partial response, stable, no response and progressive). The death and alive outcome was assessed by researcher. The survival duration of CLL patients was reported according to duration of follow up.

The data collected were analyzed statistically by Statistical Package of Social Sciences software version 22. The Chi square and Fischer's exact tests were applied for analyzing the data as suitable. Kaplan-Meier curve was used to assess the survival duration of CLL patients. Level of significance ( $p$ value) was regarded statistically significant if it was 0.05 or less. 


\section{RESULTS}

This study included 170patients with (CLL) with mean age of (66.4 years) and range of $28-88$ years; the majority $(72 \%)$ of patients were 60 years and above, and only $10 \%$ of patients were less than 50 years age. Male CLL patients were more than females $(68.8 \%$ vs. $31.2 \%)$. The residence of CLL patients was Hawler for $45.9 \%$ of them, Sulaimani for $37.1 \%$ of them and Duhok for $17.1 \%$ of them. The Binet stage of our patients was distributed as followings; stage A (33.5\%), stage B $(30.9 \%)$ and stage C (35.9\%). Rai staging of our patients was 0 in $15.3 \%$ of them, stage I in $12.4 \%$, stage II $30 \%$, stage III $13.5 \%$ and stage IV $28.8 \%$. Updated Rai classification included low risk $(15.2 \%)$, moderate risk $(42.4 \%)$ and high risk (42.4\%). (Table 1)

Table 1: General characteristics of CLL patients.

\begin{tabular}{|c|c|c|}
\hline Variable & No. & $\%$ \\
\hline \multicolumn{3}{|c|}{ Age mean $\pm S D(66.4 \pm 12.5$ years $)$} \\
\hline$<50$ years & 17 & 10.0 \\
\hline $50-59$ years & 30 & 17.6 \\
\hline $60-69$ years & 57 & 33.5 \\
\hline $70-79$ years & 34 & 20.0 \\
\hline$\geq 80$ years & 32 & 18.8 \\
\hline \multicolumn{3}{|l|}{ Gender } \\
\hline Male & 117 & 68.8 \\
\hline Female & 53 & 31.2 \\
\hline \multicolumn{3}{|l|}{ Residence } \\
\hline Hawler & 78 & 45.9 \\
\hline Sulaimani & 63 & 37.1 \\
\hline Duhok & 29 & 17.1 \\
\hline \multicolumn{3}{|l|}{ Binet stage } \\
\hline Stage A & 57 & 33.5 \\
\hline Stage B & 52 & 30.6 \\
\hline Stage C & 61 & 35.9 \\
\hline \multicolumn{3}{|l|}{ Rai staging } \\
\hline Stage 0 & 26 & 15.3 \\
\hline Stage I & 21 & 12.4 \\
\hline Stage II & 51 & 30.0 \\
\hline Stage III & 23 & 13.5 \\
\hline Stage IV & 49 & 28.8 \\
\hline \multicolumn{3}{|c|}{ Updated Rai classification } \\
\hline Low risk & 26 & 15.2 \\
\hline Moderate risk & 72 & 42.4 \\
\hline High risk & 72 & 42.4 \\
\hline Total & 170 & 100.0 \\
\hline
\end{tabular}

The FCR chemotherapy was the treatment of $37.1 \%$ of our patients, while $62.2 \%$ of the patients were treated by other chemotherapies. Mean chemotherapy treatment cycles was (5.2 cycles); $63.5 \%$ of our recruited patients received 6 cycles and more of chemotherapy treatment. The treatment response of studied sample was complete response $(43.5 \%)$, partial response $(17.6 \%)$, stable $(14.1 \%)$, no response $(21.8 \%)$ and progressive (2.9\%).

The current status of CLL patients was either dead $(29.4 \%)$, or alive $(70.6 \%)$ and the mean survival was (35.7 months); the five years overall survival was $21.2 \%$, while $78.8 \%$ of patients had survival of less than 5 years. (Table 2)

Table 2: Chemotherapy treatment and outcomes of CLL patients.

\begin{tabular}{lcc}
\hline Variable & No. & $\%$ \\
& & \\
\hline \multicolumn{2}{l}{ Chemotherapy treatment } \\
FCR & 63 & 37.1 \\
Other & 107 & 62.9
\end{tabular}

Treatment cycles mean $\pm S D(5.2 \pm 2$ cycles $)$

$<6$ cycles $\quad 62 \quad 36.5$

$\geq 6$ cycles $\quad 108 \quad 63.5$

Treatment response

Complete response $74 \quad 43.5$

Partial response $\quad 30 \quad 17.6$

$\begin{array}{lll}\text { Stable } & 24 & 14.1\end{array}$

$\begin{array}{lll}\text { No response } & 37 & 21.8\end{array}$

$\begin{array}{lll}\text { Progressive } & 5 & 2.9\end{array}$

Status

Dead $\quad 50 \quad 29.4$

Alive $\quad 120 \quad 70.6$

Survival mean $\pm S D(35.7 \pm 24.9$ months)

$\begin{array}{lll}<60 \text { months } & 134 & 78.8\end{array}$

?60months $\quad 36 \quad 21.2$

$\begin{array}{lll}\text { Total } & 170 & 100.0\end{array}$

${ }^{*}$ Other chemotherapies (Chlorambucil,

Bendamustine-Rituximab and Ibrutinib)

No significant differences were observed between CLL patients with different Rai staging regarding age $(p=0.1)$ and gender $(p=0.6)$. There was a significant association between Hawler residents of CLL patients and advanced Rai staging ( $p=0.003)$. (Table 3) 
Table 3: Distribution of CLL patients' general characteristics according to Rai staging.

\begin{tabular}{|c|c|c|c|c|c|}
\hline \multirow[t]{3}{*}{ Variable } & \multicolumn{4}{|c|}{ Rai staging } & \multirow[t]{3}{*}{$\mathbf{P}$} \\
\hline & 0 & I & II & III and IV & \\
\hline & No. (\%) & No. (\%) & No. (\%) & No. (\%) & \\
\hline Age & & & & & $0.1^{\mathrm{NS}}$ \\
\hline$<50$ years & $0(0)$ & $2(9.5)$ & $4(7.8)$ & 11 (15.3) & \\
\hline $50-59$ years & $2(7.7)$ & $8(38.1)$ & $8(15.7)$ & $12(16.7)$ & \\
\hline $60-69$ years & $11(42.3)$ & $7(33.3)$ & 17 (33.3) & $22(30.6)$ & \\
\hline $70-79$ years & $5(19.2)$ & $3(14.3)$ & $10(19.6)$ & $16(22.2)$ & \\
\hline$\geq 80$ years & $8(30.8)$ & $1(4.8)$ & $12(23.5)$ & $11(15.3)$ & \\
\hline Gender & & & & & $0.6^{\mathrm{NS}}$ \\
\hline Male & $19(73.1)$ & 12 (57.1) & 35 (68.6) & $51(70.8)$ & \\
\hline Female & $7(26.9)$ & $9(42.9)$ & $16(31.4)$ & $21(29.2)$ & \\
\hline Residence & & & & & $0.003^{s}$ \\
\hline Hawler & $6(23.1)$ & $6(28.6)$ & $20(39.2)$ & 46 (63.9) & \\
\hline Sulaimani & $13(50.0)$ & $11(52.4)$ & $23(45.1)$ & $16(22.2)$ & \\
\hline Duhok & 7 (26.9) & $4(19.0)$ & $8(15.7)$ & $10(13.9)$ & \\
\hline
\end{tabular}

$S=$ Significant, $N S=$ Not significant .

There was a significant association between FCR treatment and studied patients with advanced Rai staging $(p=0.003)$. No significant differences were observed between CLL patients with different Rai staging regarding number of treatment cycles $(p=0.6)$ and survival $(p=0.9)$. A highly significant association was observed between no response to treatment and CLL patients with advanced Rai staging $(p<0.001)$ and also a highly significant association was observed between death outcome of patients and advanced Rai staging $(p<0.001)$, deaths were mostly CLL related (Table 4)

Table 4: Distribution of CLL treatment characteristics and outcomes according to Rai staging.

\begin{tabular}{|c|c|c|c|c|c|}
\hline \multirow[t]{3}{*}{ Variable } & \multicolumn{4}{|c|}{ Rai staging } & \multirow[t]{3}{*}{$\mathbf{P}$} \\
\hline & 0 & I & II & III and IV & \\
\hline & No. (\%) & No. (\%) & No. (\%) & No. (\%) & \\
\hline Treatment & & & & & $0.003^{S}$ \\
\hline FCR & $4(15.4)$ & $8(38.1)$ & $14(27.5)$ & $37(51.4)$ & \\
\hline Other chemotherapies & $22(84.6)$ & $13(61.9)$ & 37 (72.5) & $35(48.6)$ & \\
\hline Treatment cycles & & & & & $0.6^{\mathrm{NS}}$ \\
\hline$<6$ cycles & $8(30.8)$ & $6(28.6)$ & $21(41.2)$ & $27(37.5)$ & \\
\hline$\geq 6$ cycles & $18(69.2)$ & $15(71.4)$ & $30(58.8)$ & $45(62.5)$ & \\
\hline Treatment response & & & & & $<0.001^{\mathrm{s}}$ \\
\hline Complete response & $15(57.7)$ & $16(76.2)$ & $21(41.2)$ & $22(30.6)$ & \\
\hline Partial response & $5(19.2)$ & $1(4.8)$ & $14(27.5)$ & $10(13.9)$ & \\
\hline Stable & $5(19.2)$ & $2(9.5)$ & $10(19.6)$ & $7(9.7)$ & \\
\hline No response & $1(3.8)$ & $2(9.5)$ & $6(11.8)$ & $28(38.9)$ & \\
\hline Progressive & $0(0)$ & $0(0)$ & $0(0)$ & $5(6.9)$ & \\
\hline Status & & & & & $<0.001^{\mathrm{s}}$ \\
\hline Dead & $2(7.7)$ & $3(14.3)$ & $10(19.6)$ & 35 (48.6) & \\
\hline Alive & $24(92.3)$ & $18(85.7)$ & $41(80.4)$ & $37(51.4)$ & \\
\hline Survival & & & & & $0.9^{\mathrm{NS}}$ \\
\hline$<60$ months & $21(80.8)$ & $16(76.2)$ & 39 (76.5) & $58(80.6)$ & \\
\hline$\geq 60$ months & $5(19.2)$ & $58(23.87)$ & $12(23.5)$ & $14(19.4)$ & \\
\hline
\end{tabular}

$S=$ Significant, $N S=$ Not significant . 
The overall mean survival of all treated CLL patients was 45.1 months (median=40 months), the overall mean survival of CLL patients with stage 0 was 38.2 months (median=39 months), for stage I was 43.3 months (median=41 months), for stage II was 42 months (median=29 months), for stages III and IV was 56.9 months (median=69.5 months). (Figure 1)

\section{Survival Functions}

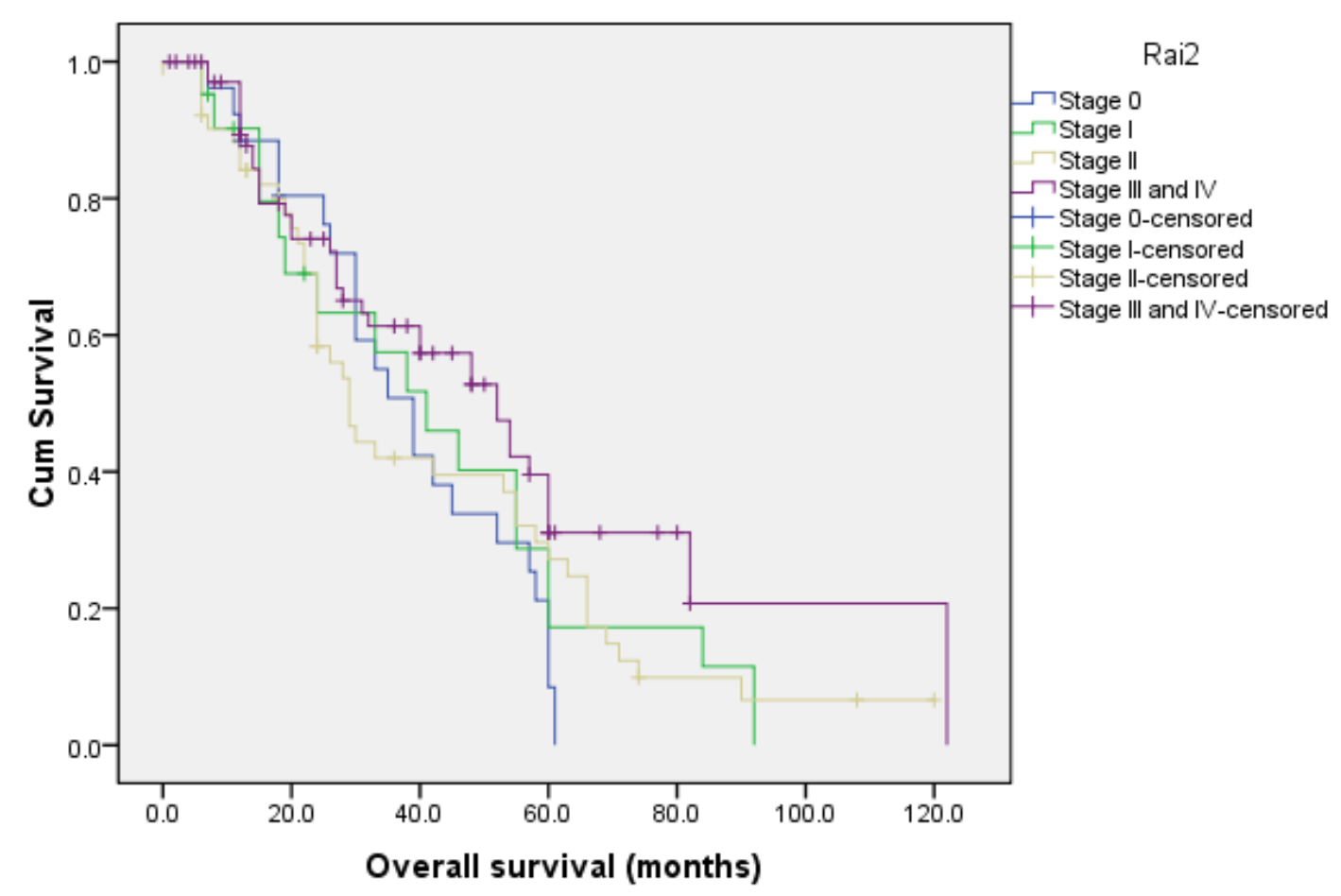

Figure 1: Kaplan-Meier curve of CLL patients according to Rai staging (blue=stage 0 ), (green=stage I), (brown=stage III), (purple=stage III and IV).

\section{DISCUSSION}

The chronic lymphocytic leukemia is the less frequent type of leukemia in Iraq ${ }^{17}$, however, about half the CLL cases in Kurdistan region are at advanced risk ${ }^{18}$.

In present study, Rai staging of studied patients was 0 in $15.3 \%$ of them, stage I in $12.4 \%$, stage II $30 \%$, stage III $13.5 \%$ and stage IV $28.8 \%$. These findings are close to results of Hasan retrospective study in Erbil city-Kurdistan on sample of 105 patients with CLL Generally, the prevalence of CLL patients at advanced Rai staging in Kurdistan is higher than other parts of Iraq ${ }^{18}$. Present study revealed that treatment response of studied sample was distributed as followings; complete response $(43.5 \%)$, partial response $(17.6 \%)$, stable $(14.1 \%)$, no response $(21.8 \%)$ and progressive $(2.9 \%)$. These findings are better than results of Naji study in Iraq ${ }^{19}$ on sample of 49 CLL patients in Baghdad teaching hospital enrolled mostly with intermediate to advanced Rai staging and reported treatment response of $12.5 \%$ complete response, $65 \%$ partial response and $22.5 \%$ no response. This difference may be due to better diagnostic and treatment facilities of Kurdistan Hemato/oncology center than other Iraqi Hemato/oncology center s. Our study findings regarding treatment response are close to results of Meunier et al ${ }^{20}$-retrospective study in France which found that overall response rate of CLL patients treated by chlorambucil, bendamustine and rituximab was $(66.2 \%)$ with complete remission of $(31.8 \%)$. The differences in treatment response of CLL are mainly related to treatment regimens used ${ }^{21}$.

The current study showed a highly significant association between no response to treatment and CLL patients with advanced Rai staging $(p<0.001)$. This finding is consistent with results of many literatures such as Rai and Jain study in USA ${ }^{22}$, Moreno et al ${ }^{23}$ study in Spain and de Faria et al ${ }^{24}$ study in Brazil which all documented that treatment response of CLL patients is directly linked to Rai 
staging of them at diagnosis. Generally, CLL patients at Rai 0 must be followed with no indication for treatment disease progression is observed. Many previous studies carried out in Western countries reported that survival of patients with low risk CLL (early stage) was not prolonged after treatment by alkylating agents ${ }^{25-28}$.Dighiero et al ${ }^{25}$ found that incidence of epithelia cancer was higher among treated CLL patients at low risk in comparison to untreated CLL patients at low risk.Our study found also highly significant association was observed between death outcome of patients and advanced Rai staging $(p<0.001)$. This finding coincides with results of Velez et al ${ }^{29}$ study in USA which stated that advanced Rai staging (stages III and IV) of patients with chronic lymphocytic leukemia were significantly had higher mortality rates and high risk of other cancers like skin cancer.In Spain, a study conducted by Villavicencio et al ${ }^{30}$ revealed a significant association between Rai staging and Charlson comorbidity index of patients with CLL and patients with advanced Rai staging were more prone for comorbidities and higher death rates. However, our study showed no significant relationship between survival of CLL patients and Rai staging. This finding is inconsistent with results ofde Faria et al 24 study in Brazil which reported a significant association between advanced Rai staging of patients with CLL and shorter survival. This inconsistency might be due to difference in health infrastructure and discrepancy in diagnostic techniques between Hemato/oncology center $s$ of different countries.

Our study also showed variations in survival of studied patients according to Rai staging; however, the overall mean survival of all treated CLL patients was 45.1 month. This finding is lower than results of Hasan study in Erbil city-Kurdistan which reported over all mean survival of (60 months) ${ }^{18}$. This difference might be attributed to difference in inclusion criteria between two studies as our study included treated CLL patients only.

In present study, there was a significant association between FCR treatment and studied patients with advanced Rai staging $(p=0.003)$. This finding is similar to results of Herling et al ${ }^{31}$ study in UK which documented that early FCR treatment for patients with low risk CLL is not useful in changing the outcome and survival of patients, while it is effective in patients with high risk (advanced Rai staging). Our study also showed a significant association between Hawler residents of CLL patients and advanced Rai staging ( $p=0.003)$. This fact might be due to fact that Hawler city is the Capital of Kurdistan region that made it the recipient of all referred advanced Rai staging CLL cases from other Hemato/oncology center $s$ in other cities.

In conclusion, the treatment response of patients with chronic lymphocytic leukemia is directly related to Rai staging as patients with advanced Rai staging had lower treatment response rate. The Rai staging is an optimal guideline for treatment regimen selection and final outcome of patients with CLL. Our study urged the Oncologist to adopt the clinical staging systems as the basic steps in treatment planning and prognosis for chronic lymphocytic leukemia.

\section{Acknowledgment}

Great thanks to all medical health staff working in Hemato/oncology center s in Kurdistan for their efforts and help to complete my research.

\section{Conflict Of Interest \\ Declared none.}

\section{REFERENCES}

1.DeSantis CE, Lin $C C$, Mariotto $A B$, Siegel $R L$, Stein KD, Kramer JL, et al. Cancer treatment and survivorship statistics, 2014. CA Cancer J Clin 2014; 64(4):252-271. doi: 10.3322/caac.21235.

2. Yamamoto JF, Goodman MT. Patterns of leukemia incidence in the United States by subtype and demographic characteristics, 19972002. Cancer Causes Control 2008; 19(4):379390. doi: 10.1007/s10552-007-9097-2.

3.Siegel RL, Miller KD, Jemal A. Cancer statistics, 2015. CA Cancer J Clin 2015; 65(1):5-29. doi: 10.3322/caac.21254.

4.Lanasa MC. Novel insights into the biology of CLL. Hematology Am Soc Hematol Educ Program 2010; 2010:70-76. doi: 10.1182/asheducation-2010.1.70.

5. Chiorazzi N, Ferrarini M. Cellular origin(s) of chronic lymphocytic leukemia: cautionary notes and additional considerations and possibilities. Blood 2011; 117(6):1781-1791. doi: 10.1182/blood-2010-07-155663.

6. Rozman C, Montserrat E. Chronic lymphocytic leukemia. N Engl J Med 1995; 333(16):10521057. doi: 10.1056/NEJM199510193331606.

7. Rai KR, Sawitsky A, Cronkite EP, Chanana AD, Levy RN, Pasternack BS. Clinical staging of chronic lymphocytic leukemia. Blood 1975; 46(2):219-234. PMID: 1139039.

8. Binet JL, Auquier A, Dighiero G, Chastang C, Piguet $\mathrm{H}$, Goasguen J, et al. A new prognostic classification of chronic lymphocytic leukemia derived from a multivariate survival analysis. Cancer 1981; 48(1):198-206. doi: 10.1002/1097- 
0142(19810701)48:1<198::aidcncr2820480131>3.0.co;2-v.

9. Rodrigues CA, Gonçalves MV, Ikoma MR, Lorand-Metze I, Pereira AD, Farias DL, et al; Brazilian Group of Chronic Lymphocytic Leukemia. Diagnosis and treatment of chronic lymphocytic leukemia: recommendations from the Brazilian Group of Chronic Lymphocytic Leukemia. Rev Bras HematolHemoter 2016; 38(4):346-357. doi: 10.1016/j.bjhh.2016.07.004.

10. Swerdlow SH, Campo E, Harris NL, Jaffe ES, Pileri SA, Stein H, et al. IARC Press; Lyon: 2008. WHO classification of tumours of hematopoietic and lymphoid tissues.

11. Montserrat E, Rozman C. Bone marrow biopsy in chronic lymphocytic leukemia: a review of its prognostic importance. Blood Cells 1987; 12(2):315-326. PMID: 3304470.

12. Nabhan C, Rosen ST. Chronic lymphocytic leukemia: a clinical review. JAMA 2014; 312(21):2265-2276.

10.1001/jama.2014.14553.

13. Damle RN, Wasil T, Fais F, Ghiotto F, Valetto A, Allen SL, et al. Ig V gene mutation status and CD38 expression as novel prognostic indicators in chronic lymphocytic leukemia. Blood 1999; 94(6):1840-1847. PMID: 10477712.

14. Hallek M, Cheson BD, Catovsky D, CaligarisCappio F, Dighiero G, Döhner H, et al. iwCLL guidelines for diagnosis, indications for treatment, response assessment, and supportive management of CLL. Blood 2018; 131(25):27452760. doi: 10.1182/blood-2017-09-806398.

15. Burger JA, Barr PM, Robak T, Owen C, Ghia $P$, Tedeschi $A$, et al. Long-term efficacy and safety of first-line ibrutinib treatment for patients with CLL/SLL: 5 years of follow-up from the phase 3 RESONATE-2 study. Leukemia 2020; 34(3):787-798. doi: 10.1038/s41375-019-0602-x.

16. Byrd JC, Furman RR, Coutre SE, Flinn IW, Burger JA, Blum K, et al. Ibrutinib Treatment for First-Line and Relapsed/Refractory Chronic Lymphocytic Leukemia: Final Analysis of the Pivotal Phase Ib/ll PCYC-1102 Study. Clin Cancer Res 2020; 26(15):3918-3927. doi: 10.1158/1078-0432.CCR-19-2856.

17. Naji A. Outcome of 49 Iraqi adult patients with Chronic Lymphocytic Leukemia treated with oral alkylating agent. J Fac Med Bagdad 2021; 54(2):126-30. Available from: https://iqjmc.uobaghdad.edu.iq/index.php/19JFa cMedBaghdad36/article/view/

18. Hasan KM. Clinical Aspects, Immunophenotypic Analysis and Survival Rate of Chronic Lymphocytic Leukemia Patients in Erbil City, Iraq. Sultan Qaboos Univ Med J 2018; 18(4):e461-e467.

10.18295/squmj.2018.18.04.006.
19. Al Tameemi WF. Efficacy of combination of rituximab therapy with chlorambucil plus prednisolone (R-LP) Protocol as treatment line in chronic lymphocytic leukemia patients. Iraqi J Hematology 2015; 4 (1): 1-15.

20. Meunier G, Ysebaert L, Nguyen-Thi PL, Lepretre S, Quinquenel A, Dupuis J, et al. Firstline therapy for chronic lymphocytic leukemia in patients older than 79 years is feasible and achieves good results: A FILO retrospective study. Hematol Oncol 2017; 35(4):671-678. doi: 10.1002/hon.2370.

21. Tresckow JV, Eichhorst B, Bahlo J, Hallek M. The Treatment of Chronic Lymphatic Leukemia. Dtsch Arztebl Int 2019; 116(4):41-46. doi: 10.3238/arztebl.2019.0041.

22. Rai KR, Jain $P$. Chronic lymphocytic leukemia (CLL)-Then and now. Am $\mathrm{J}$ Hematol 2016; 91(3):330-340. doi: 10.1002/ajh.24282.

23. Moreno C, Delgado J, Byrd JC, Zvagelsky WL, Suzuki S, Hsu E, et al. Changes in clinical stage identify patients with CLL and different outcome within iwCLL partial response: RESONATE study. $\mathrm{Br} J$ Hematol 2019; 185(1):148150. Available from: https://doi.org/10.1111/bjh.15397

24. de Faria JR, de Oliveira JS, Delbone de Faria RM, Silva MR, Goihman S, Yamamoto M, et al. Prognosis related to staging systems for chronic lymphocytic leukemia. Sao Paulo Med J 2000; 118(4):83-88. doi: 10.1590/s151631802000000400002.

25. Dighiero G, Maloum K, Desablens B, Cazin B, Navarro $M$, Leblay $R$, et al. Chlorambucil in indolent chronic lymphocytic leukemia. French Cooperative Group on Chronic Lymphocytic Leukemia. N Engl J Med 1998; 338(21):150614. doi: $10.1056 /$ NEJM199805213382104.

26. Shustik C, Mick R, Silver R, Sawitsky A, Rai K, Shapiro $\mathrm{L}$. Treatment of early chronic lymphocytic leukemia: intermittent chlorambucil versus observation. Hematol Oncol 1988; 6:712. doi: 10.1002/hon.2900060103.

27. Montserrat E, Fontanillas $M$, Estape $J$ for the Spanish PETHEMA Group. Chronic lymphocytic leukemia treatment: an interim report of PETHEMA trials. Leuk Lymphoma 1991; 5:8992. doi: $10.3109 / 10428199109103385$.

28. CLL Trialists' Collaborative Group. Chemotherapeutic options in chronic lymphocytic leukemia: a meta-analysis of the randomized trials. J Natl Cancer Inst 1999; 91:861-868. Available from: https://doi.org/10.1093/inci/91.10.86

29. Velez NF, Karia PS, Vartanov AR, Davids MS, Brown JR, Schmults CD. Association of advanced leukemic stage and skin cancer tumor stage with poor skin cancer outcomes in patients 
with chronic lymphocytic leukemia. JAMA Dermatol 2014; 150(3):280-287. doi: 10.1001/jamadermatol.2013.6249.

30. Villavicencio A, Solans M, Zacarías-Pons L, Vidal A, Puigdemont M, Roncero JM, et al. Comorbidities at Diagnosis, Survival, and Cause of Death in Patients with Chronic Lymphocytic Leukemia: A Population-Based Study. Int J Environ Res Public Health 2021; 18(2):701. doi: 10.3390/ijerph18020701.

31. Herling CD, Cymbalista F, Groß-Ophoff-Müller C, Bahlo J, Robrecht S, Langerbeins $P$, et al. Early treatment with FCR versus watch and wait in patients with stage Binet $A$ high-risk chronic lymphocytic leukemia (CLL): a randomized phase 3 trial. Leukemia 2020; 34(8):2038-2050. doi: 10.1038/s41375-020-0747-7. 